\title{
El estereotipo del bárbaro y la imagen de la civilización en el occidente romano en la Geografía de Estrabón
}

\author{
The barbarian's stereotype and the idea of civilization \\ in the Western Roman empire in Strabo's Geography
}

\author{
IVÁN GonZÁLEZ BALLESTEROS*
}

\begin{abstract}
RESUMEN
En la presente comunicación pretendemos realizar un acercamiento al estereotipo existente en el mundo helenístico y romano de aquellos pueblos denominados bárbaros, haciendo especial hincapié en las regiones más occidentales del Imperio - Hispania, Galia, Germania, Britania-, bajo la óptica de Estrabón. Por oposición, también analizaremos la visión de lo que se entendía por civilización.
\end{abstract}

PALABRAS CLAVE:

Historia Antigua, Imperio Romano, romanización, Estrabón.

\begin{abstract}
In the present communication we want to make an approach to the existing stereotype, in the Hellenistic and Roman world, of the so-called 'Barbarian' peoples, with some emphasis in the Western regions of the Empire - Hispania, Gaul, Germania, Britannia-, from Strabo's point of view. We will also study the concept of 'civilization' for the Romans.
\end{abstract}

KEYWORDS:

Ancient History, Roman Empire, Romanization, Strabo.

\section{INTRODUCCIÓN}

Estrabón recurrió al conocimiento geográfico existente en los siglos II y I antes de Cristo para elaborar una obra magistral en época augústea, la Geografía, que constituyó un auténtico compendio del saber de su época. Se reunían así de forma crítica las aportaciones de eruditos anteriores como Polibio, Artemidoro o Posidonio. De esta forma, la obra magna de Estrabón deviene en un compendio crítico no

* Facultad de Ciencias de la Educación y Humanidades, Universidad de Castilla-La Mancha (Avda de los Alfares, 44.16071 Cuenca). E-mail: Ivan.Gonzañez@uclm.es.

Artículo basado en la comunicación leída el 25 de Mayo de 2009, en la VIII edición del Encuentro de Jóvenes Investigadores de Historia Antigua de la Universidad Complutense de Madrid. 
sólo del saber topográfico, sino también del histórico, mitológico, antropológico, astronómico, biológico, agrícola, físico y matemático de su tiempo, resultando para nosotros de especial interés, para el asunto que nos ocupa, las noticias que aparecen en referencia a las formas de vida de aquellos pueblos considerados como bárbaros en el occidente del Imperio romano.

Hay que señalar, como el mismo Estrabón reconocía, que jamás estuvo en varios de los lugares que describió, como es el caso de nuestro ámbito de estudio, el occidente del Imperio romano - Hispania, Galia, Britania, Germania-. Del mismo modo, afirmaba que intentó suplir esa carencia de información de primera mano con abundantes informes de otros estudiosos y viajeros. Esta circunstancia, que a priori podría suponer un inconveniente, para nosotros se convierte en una oportunidad para conocer la visión que se tenía en la sociedad romana del cambio de Era de aquellos pueblos bárbaros que se iban integrando en la romanidad.

Estrabón contrapuso a esa imagen del pueblo no civilizado, cargada de estereotipos, la de aquellos que encarnaban la civilización propiamente dicha, con el fin de destacar sus virtudes y poner de manifiesto la inferioridad del resto. Así, no dudó en presentar el modo de vida griego como el ideal más perfecto que pudiera encontrarse, como bien podemos observar en su descripción de Masalia (4.1.5). En su defecto, defendía el modo de vida romano, que se iba ampliando hacia el exterior y consolidando en el interior, en un ejercicio de 'corrección política' y aprobación de la política augustea. No dudó Estrabón en sazonar su relato con numerosos ejemplos de amistad grecorromana y de las más evidentes -y escandalosas - diferencias entre su existencia, la civilizada, y la de los pueblos conquistados, la bárbara.

Como vemos, el sometimiento del mundo griego a Roma no era únicamente político, sino también intelectual. Con ello, observamos un constante tono laudatorio hacia el germen del personalista poder imperial -César y Augusto-y sus formas más representativas — la divinización, el culto imperial-. Se cantaban también las glorias de la pax romana, justificando de paso cualquier actuación militar para garantizarla. Asimismo, el progresivo establecimiento de colonias romanas por las tierras conquistadas era aprobado, ya que se convierten en focos de prosperidad. De cualquier forma, hemos creído que bajo este manto conformista, se esconden varias críticas subrepticias hacia el mundo romano, y que desarrollaremos más adelante.

\section{EL DETERMINISMO GEOGRÁFICO EN EL MUNDO GRIEGO}

\subsection{Civilización contra barbarie}

La diferenciación entre barbarie y civilización era una constante en la cultura griega desde varios siglos antes del nacimiento de Estrabón. Fueron los sofistas los que plantearon la dualidad entre phýsis y nómos, que irá implantándose en el imaginario colectivo griego y que se plasmará en la división de la humanidad entre 
hombres bárbaros y hombres civilizados. De esta manera, tendríamos un pueblo, el griego, capaz de realizar elevadas obras intelectuales, y al resto, focalizados en actividades más físicas; fruto de este planteamiento observamos que los helenos son capaces de desarrollar industrias avanzadas, el comercio, las artes, o la elaboración de un sistema político adecuado, en un claro reflejo de la Política de Aristóteles. Por extensión, la democracia y la organización en póleis serían los principales índices de civilización.

\subsection{Las tesis del determinismo}

Según las teorías deterministas, el clima jugaba un factor importante en el desarrollo de las culturas: los climas templados favorecen el desarrollo natural del hombre, pero los que son muy fríos o muy calientes hacen que la vida se vuelva más difícil, conduciendo al ser humano a la barbarie. Posidonio puso en relación los climas y el desarrollo - o ausencia- de cultura, teoría recogida por Estrabón, si bien no la compartió plenamente. Según las observaciones del de Ponto, había otros muchos pueblos que disfrutaban de climas templados pero seguían siendo bárbaros - no obstante pertenecientes a las altas culturas bárbaras-, como caldeos, cartagineses, egipcios o fenicios; de esta manera llegó a la conclusión de que el clima nunca favorecía para bien, sino que más bien se convertía en una condición previa que permitía el desarrollo de la civilización.

Otro factor relevante era la riqueza, ya que si el territorio que ocupaba un pueblo poseía las suficientes riquezas, la vida resultaba más sencilla. Así se favorecía el desarrollo de la civilización, de una forma similar a como lo hacía el clima. Por el contrario, tanto el exceso como el defecto de las riquezas resultaba perjudicial: si el territorio era ubérrimo, sus habitantes caían en la molicie y no se preocupaban por mejorar su existencia; por otra parte, si el territorio era miserable, la misma existencia del hombre se encontraría en peligro.

A fines del siglo $V$ a.C. apareció un tratado médico, de autor anónimo, bajo el título Sobre los aires, las aguas, los lugares. Se trata de un texto fundamental para comprender el determinismo geográfico que impregnó durante siglos las teorías de los científicos y pensadores griegos - Jenofonte, Aristóteles, Agatárquides, Polibio, Posidonio o incluso Vitruvio-, y que condensa todas las anteriores ideas al respecto; tesis que, indudablemente, influyó en Estrabón, pero como hemos visto, con matizaciones. Según este tratado, en Asia tendríamos un territorio que, por las bondades de su clima, daba abundantes productos de calidad; en contrapartida, sus habitantes cayeron en la molicie y se volvieron blandos y cobardes al no estar acostumbrados al sufrimiento. En Europa el clima era más duro, por lo que los pueblos tenían que esforzarse por prosperar, bien sirviéndose de la civilización, como los griegos, bien utilizando la violencia, como muchos bárbaros, con su bandidaje y piratería. 


\subsection{La superación del determinismo en Estrabón}

Los griegos creían en el determinismo geográfico, aunque no lo entendían como insalvable, ya que factores como los anteriormente descritos podían ser condicionantes, tanto a favor como en contra, pero nunca completamente decisorios. Para ellos, el hombre verdaderamente civilizado era aquél que poseía la voluntad suficiente como para abrirse paso en cualquier medio, explotando adecuadamente sus recursos -a través de la agricultura, hecho diferenciador entre civilización-barbarie-, y quedando toda la sociedad organizada según el sistema político griego de póleis.

Los eruditos también observaron la capacidad de influencia de la propia civilización sobre los pueblos bárbaros. Los griegos primero, y los macedonios y los romanos después, se convertirían con el tiempo en los estandartes del progreso, ampliando mediante sus sucesivas campañas militares los límites de lo considerado como mundo civilizado. Entendido de esta forma, la expansión militar más allá de los territorios propios comporta llevar cada vez más lejos la civilización, lo que se convertía en una clara defensa del imperialismo en el mundo antiguo.

Estrabón entró en conflicto con Posidonio por su posicionamiento ante las teorías deterministas. Así, podemos observar en los dos primeros libros de la Geografía cómo reconocía el peso del entorno en el desempeño de un pueblo, pero no le concedía un papel definitivo, criticando de esta forma a Posidonio (2.3.7; 2.5.26). De este modo, los bárbaros podrían acabar siendo admitidos dentro del mundo civilizado, que era exactamente la labor de la romanización: transformar a los salvajes indígenas en individuos que han asumido la cultura y los modos de vida romanos. Y esto sucede con la intervención de idénticos factores climáticos y ambientales en la misma población. Ejemplos no nos faltan, como en es caso de los celtíberos, muy avanzado (3.4.20), o los cántabros, en sus inicios (3.3.8).

Por otra parte, Estrabón también se mostró contrario a los postulados de Posidonio con respecto a la vida del bárbaro al margen de la civilización. El segundo defendía las bondades del hombre en su estado natural, como haría Rousseau muchos siglos más tarde, mientras que el de Ponto argumentaba que los bárbaros son salvajes, y que, o bien eran civilizados, o bien se acabarían destruyendo a sí mismos por los comportamientos salvajes que conlleva la barbarie.

\section{IMÁGENES ESTEREOTÍPICAS DEL BÁRBARO}

A continuación abordaremos los principales rasgos diferenciadores que separaban al salvaje del hombre civilizado.

\subsection{La alimentación}

Uno de los puntos a los que Estrabón dedicó más atención en su obra es aquél en el que refiere los usos y costumbres alimenticios de los pueblos indígenas de 
Occidente. El fin perseguido por el autor era doble: por un lado, mostrar al lector la curiosidad antropológica, la anécdota; por el otro, profundizar en la conformación del estereotipo del bárbaro, encargándose de distinguirlo lo más posible del hombre civilizado.

Según los parámetros culturales griegos, se consideraba un indicio de civilización que la agricultura de un pueblo se articulase fundamentalmente en torno al cultivo del trigo, del olivo y de la vid. Su desarrollo comportaba la integración del pueblo en el ámbito mediterráneo, en la zona templada y, por tanto, que permitía el desarrollo de la civilización. En aquellas regiones donde estos cultivos no prosperaban, no se podría desarrollar la civilización, con lo que no eran lugares adecuados para vivir plenamente. Sí se desarrollaban en estas malas regiones los pueblos bárbaros, pero al no tener acceso al trigo, al aceite y al vino, no se les puede considerar civilizados. De este modo, Estrabón enlaza las circunstancias ambientales —climáticas y edafológicas- con el desarrollo de la civilización.

Como ya hemos visto, estos elementos condicionantes no son en absoluto decisorios: el autor señaló directamente a los turdetanos, situados en el borde de la Oikouméne y productores de trigo, aceite y vino, pero que seguían siendo bárbaros, ya que mantenían algunas de sus costumbres salvajes. Por otra parte, entre los pueblos considerados como altas culturas bárbaras, que se encuentran libres de casi todas las acusaciones de salvajismo, carecen de algunos - cuando no de todos- los cultivos de la trilogía mediterránea, si bien se muestran dispuestos a adquirirlos como una forma de aproximación a la civilización. También hay culturas que producen o consiguen sucedáneos, como la cerveza para el vino, la mantequilla para el aceite, o la cebada, el centeno y la bellota para el trigo.

\subsubsection{El cultivo del trigo}

El continuo hincapié de Estrabón en el respeto al cultivo de la trilogía mediterránea tenía una connotación más allá de su identificación con un ámbito climático determinado, suponía también una muestra de piedad hacia los dioses. De este modo, el cultivo del trigo y la utilización del pan de este cereal, considerado superior, suponía una forma de rendir culto a la diosa Démeter. La utilización de otros cereales no dejaba de ser un triste sustitutivo del original, pero el caso resultaba aún más sangrante cuando la harina utilizada era de bellotas. Su uso por un pueblo - por ejemplo, los del norte de lberia- significaba que se encontraban en un nivel de atraso tan grande, que ni siquiera conocían la agricultura más básica. El autor no se preocupaba por indagar si utilizaban otro tipo de cultivos - por ejemplo, leguminosas-, sino que la misma falta del trigo en la dieta era motivo de gran escándalo. Este cereal resultaba fundamental en la concepción griega de la civilización: su introducción trajo el uso del fuego e inició el orden social; incluso la misma diosa, Démeter, que daba el trigo, trajo el matrimonio y las leyes (se vinculan así trigo, matrimonio y orden social). Si faltaba este alimento, el matrimonio y el buen orden social se volverían extraños. 


\subsubsection{El cultivo del olivo}

Mayores connotaciones en ese aspecto tenía el olivo, ya que se consideraba el árbol por excelencia de Atenea, paradigma de la inteligencia y la civilización: allá donde la planta se desarrollase, alcanzarían los dones de la deidad. Por ello, su sustitución por la mantequilla, de origen animal, resultaba tan ofensivo para la mentalidad griega como rechazar las bendiciones de la divinidad y la civilización.

\subsubsection{El cultivo de la vid}

Pero, sin duda, eran la vid y el vino los más decisorios indicios de civilización en la categoría alimenticia. El vino era un elemento civilizador claramente deseado por los bárbaros, aunque nunca se les llegó a etiquetar de alcohólicos. Su más común sucedáneo, la cerveza, no era considerada de forma completamente negativa por los griegos, ya que algunas de las altas civilizaciones bárbaras, como Egipto, la consumían. El vino representaba un lado oscuro de desenfreno -como el mismo Dionisos-, que el propio dios dosifica, como hacían los griegos; los bárbaros eran incapaces de alcanzar dicha dosificación, ahí residía la diferencia entre unos y otros. Se apreciaban similitudes entre las bacantes, que recaen una y otra vez en el desenfreno sin control, y los bárbaros - su papel en la difusión de cultos, su aspecto con cabellos largos y barbas (Strab. 3.3.7, 4.4.3, 7.3.4), pantalones (Strab. 4.4.3), sagi (Strab. 3.3.7), ropas multicolores, etc.

\subsubsection{Los usos del vino}

Resultaba especialmente chocante para Estrabón que no se realizasen ceremonias como el symposion griego para su consumo solemne; de este modo podemos observar un fuerte contraste entre la modalidad de 'banquete' bárbara y la que se consideraba canónica. El symposion era una celebración típicamente helénica en la que se reunían los ciudadanos libres e iguales, sin jerarquías - hasta el simposiarca era elegido-, para consumir el vino recostados mientras se disfrutaba de la poesía y la filosofía. El vino se mezclaba con agua, a modo de segunda 'domesticación' del fruto de la vid -la primera sería la transformación del mosto en vino- y se celebran rituales en honor a Dionisos. Como vemos, todo el ritual del symposion se identificaba como un rito intrínsecamente griego.

Por el contrario, en el festín bárbaro se reunían las familias, organizadas según edades y jerarquía, donde se consume comida y bebida; esa bebida puede ser, o bien cerveza, o bien vino sin rebajar. Durante el banquete, que se celebra con la gente sentada, se realizan bailes y canciones bárbaras, tan chocantes para la óptica de Estrabón. Bien es cierto que se buscaban similitudes con los banquetes de los espartanos o de los cínicos en cuanto a la sobriedad de los indígenas, por otra 
parte una constante en varios pueblos peninsulares, pero Estrabón no se sintió inclinado a señalar esta identidad: el contraste entre ambos ceremoniales era demasiado fuerte y profundo, y a varios niveles. Parece ser que el autor pretendía señalar que el banquete bárbaro era un triste -incluso podríamos añadir que infantil- remedo de symposion.

En un nivel más profundo, observamos que Estrabón comparó, mediante el contraste entre ambas celebraciones, los dos tipos de sociedad: las sociedades democráticas organizan el symposion, epítome de la civilización; los bárbaros, el banquete jerarquizado. Con esto, podemos colegir, la forma de gobierno determinaría la capacidad de organizar bien o mal el symposion, muy posiblemente porque en el esquema mental de Estrabón era inherente a la democracia griega y por ello no se puede dar en otras formas de gobierno. En este caso, aún nos faltaría un punto de análisis: ¿y qué hay de Roma? ¿Cómo lo organizaban? ¿A la manera griega, como los bárbaros o un punto intermedio? El silencio del autor al respecto resulta, cuanto menos, sospechoso.

\subsubsection{Otros alimentos}

Otro alimento que marcaba diferencias entre griegos y bárbaros era el consumo de leche. Beber leche resultaba completamente natural para los griegos, pero el consumo en exceso era una costumbre propia de los bárbaros, como por ejemplo los galos (Strab. 4.4.3). El mismo comportamiento se les atribuía con respecto a la carne, consumida igualmente en grandes cantidades. También había ciertas reservas en cuanto al consumo de determinadas carnes; así la cabra, representaba, en el imaginario griego, una ganadería de segunda categoría, ya que es un animal que no necesita un pastoreo tan cuidadoso como el de la oveja. Su utilización significa cierta incapacidad de alcanzar una ganadería digna de recibir tal nombre.

\subsubsection{Antropofagia}

Considerada en la época como el hábito más extremo del salvajismo, sólo se daba en los pueblos más alejados de la civilización, donde las condiciones de la existencia eran muy duras. En nuestro ámbito de estudio, lo podemos contemplar en Yerne (Strab. 4.5.4), actual Irlanda, donde el primitivismo del hombre y su salvajismo adoptan su máxima expresión: los hombres copulaban con las mujeres a la vista de todos y sin importarles los lazos de sangre que pudieran haber entre ellos, apenas cubrían sus cuerpos con pieles, y practicaban la antropofagia, llegando Estrabón al extremo de indicar que estaba bien visto entre estos pueblos el comerse los cadáveres de los ancestros. 


\subsection{Las creencias}

\subsubsection{Ateísmo}

La impiedad no es más que un atributo más del estereotipo del bárbaro que se manejaba en el mundo clásico grecorromano. La adoración de dioses que no fueran los del Panteón Olímpico o de aquellos que, aun siendo ajenos a él, eran aceptados socialmente - Cibeles, Isis, Mitra-, producía un profundo rechazo entre los habitantes del mundo civilizado hacia los pueblos bárbaros. Las soluciones que se planteaban ante este conflicto solían presentar dos vertientes: el sincretismo religioso o el rechazo absoluto. El primero de ellos, fundamental en el proceso de romanización, se llevaba a cabo cuando la identidad entre el dios 'civilizado' y el dios 'bárbaro' podía establecerse a través de sus ámbitos de actuación y atributos; de este modo, la veneración de un pueblo recién conquistado hacia un dios de la guerra desembocaba en la presunción de que se trataba de un culto relativamente primitivo hacia Ares/Marte. Un ejemplo icónico de este comportamiento lo refleja Estrabón al hablar de los lusitanos (3.3.7).

La segunda alternativa se dio en aquellas ocasiones en las que el contraste entre las creencias 'civilizadas' y las 'bárbaras' era tan profundo que la reacción ante el choque cultural desembocaba en la negación y rechazo profundos de esos cultos. De este modo, la adoración a dioses que no tuvieran paralelismo posible con los propios terminaba con la acusación de ateismo, que justo es el caso que tenemos aquí con los galaicos (3.4.16). Esto, por una parte, demostraba lo rígidas que resultaban las concepciones grecorromanas en materia religiosa para todo aquello que se saliera del ámbito habitual; por otra parte, nos señala que los galaicos, más que ateos, serían veneradores de las fuerzas de la naturaleza - tormenta, sol, lluvias-. Una vez más, se trata de un intento de señalar las salvajes costumbres de los 'bárbaros' en contraposición al mundo 'civilizado'.

\subsubsection{Sacrificios}

Formaba parte de la mentalidad griega que los bárbaros realizasen sacrificios humanos, de hecho se lo atribuyen por igual a escitas, celtas, germanos, cartagineses, etc., con un propósito claramente despectivo. Estrabón lo atestigua para los lusitanos (3.3.7), así como lo hacen Diodoro (5.31.3), Julio César (BG 6.16.3), Tácito (An. 14.30) o Amiano (27.44) entre los celtas, siempre relatándolo de la forma más truculenta y cruel posible. En la cultura grecolatina era perfectamente lógico sacrificar con fines adivinatorios y militares, así como examinar las entrañas, ver cómo manaba la sangre o caía el sacrificado, especialmente entre los romanos. Se puede decir que los bárbaros hacían el rito adecuadamente persiguiendo el fin correcto; el inconveniente era que se sirvieran de hombres para la realización de estas prácticas. Otro tanto sucedía con el caballo, que sólo se utilizaba en casos muy concretos. 


\subsection{La higiene}

Es muy conocido el pasaje de Estrabón en el que relata cómo los indígenas se lavaban los dientes con sus orines (3.4.16). Como podemos suponer, no expone el texto de forma neutral, sino que buscaba el desprestigio de los indígenas hispanos, ya que se trata de un hábito contrario a toda forma de higiene; esto permitiría justificar el sometimiento y civilización de estos pueblos por Roma. Pero no es un caso único, ya que esta costumbre también es atribuida por Diodoro Sículo (5.33) a los celtíberos - señalando que la utilizaban por añadidura como jabón-, haciendo Catulo $(37.20,39.17 s s$.) referencia a ello en su obra. Pero nos asalta una pregunta: ¿Se trata de algo real o bien es una pretensión de los autores para mostrar el grado de salvajismo en el que viven los bárbaros?

En la actualidad existen pueblos ganaderos que utilizan la orina de animales, como los nuer (Sudán, Etiopía) o los masai (Kenia, Tanzania), para batir la manteca y la elaboración de queso, pero también le dan un uso higiénico. Lo cierto es que, en nuestra civilización, hábitos de este tipo producen, en el mejor de los casos, sorpresa, por lo que podríamos pensar que, para los romanos, la situación sería similar. Pero la gran diferencia era que la relación de los latinos con las excreciones era distinta a la nuestra, y su utilización con los más diversos fines está más que documentada. Así, podemos observar que en Roma existían divinidades, o advocaciones de las mismas, referidas a los excrementos, como Cloacina, o Venus/Concordia Cloacina, o Stercus/Sterculius, o Saturno Stercus/Sterculius, lo que nos da una idea del trato diferente que se les daba.

Adentrándonos en un ámbito más científico, podemos leer que Plinio en su Historia Natural (28) recomendaba la utilización de los orines de todo tipo de animales bajo el supuesto de que cada uno podría sanar una dolencia determinada; o lo que es lo mismo, la utilización de la orina con fines terapéuticos era, cuanto menos, aceptado en Roma. En este caso, ¿incurría entonces Estrabón en una contradicción al acusar de salvajes a los indígenas de Iberia por seguir conductas que también se presentaban en el mundo 'civilizado'? A primera vista podría parecer que sí, pero si profundizamos un poco más en el tema podemos encontrarnos con que el aparente contrasentido no lo es tanto.

Tras la crítica de Estrabón a los bárbaros se esconde otra mayor hacia los propios romanos. El hecho de señalar como salvaje una costumbre ampliamente practicada por los latinos podía ser una forma de poner cierta distancia entre el mundo griego helenístico al que pertenecía y el mundo romano. Razones para hacer algo así no le faltarían, no debemos olvidar la reciente anexión por Roma de Ponto, su lugar de origen, ni el sentimiento de superioridad cultural -entre otrosque embargaba a los griegos con referencia a los restantes pueblos. De este modo, este pasaje podría tener un doble fin: remarcar el salvajismo de algunos pueblos indígenas hispanos, y señalar de paso la preservación de costumbres muy similares entre los que se dicen 'civilizados' sin serlo completamente. 


\subsection{La sociedad}

\subsubsection{Pena de muerte}

Según Estrabón (3.3.7), los indígenas hispanos «despeñan a los condenados a muerte, lapidan a los parricidas más allá de las montañas y los cursos de agua». Arrojar por precipicios a aquellos condenados a muerte no era una costumbre para nada ajena a las leyes grecorromanas. Así, los griegos se servían del katakremnismós, que implicaba despeñar a los reos de muerte en una especie de juicio divino, de tal forma que, en caso de que el precipitado fuera verdaderamente inocente del crimen del que se le acusaba, quedaba al albedrío de los dioses salvarlo. Por otra parte los romanos usaban la roca Tarpeya para ejecutar a los condenados a muerte, y también hay testimonios de despeñamientos como forma de ejecución entre pueblos tan dispares como germanos o judíos, entre muchos otros.

Para el parricidio, la pena romana (Justiniano Instituciones 4.18) consistía en introducir al reo en un odre, en el que previamente se habían introducido un mono, un perro, un gallo y una víbora, coserlo y arrojarlo a un río. El fin de este castigo, que tenía un fuerte componente simbólico, era separar al condenado del cielo y la tierra, del mundo de los vivos y del mundo de los muertos, dejándolo apartado en una especie de limbo permanente. En esto no es muy distinto de las prácticas indígenas, que lapidaban al culpable más allá de los territorios de la comunidad con dos fines: evitar que su sangre mancillase la tierra y separarlo del resto del clan, de forma física primero, espiritual después. Como vemos, el fin resulta idéntico, si bien según la óptica grecorromana la práctica indígena resultaba más rudimentaria y menos sofisticada.

\subsubsection{El matrimonio}

En lo concerniente al asunto del matrimonio, Estrabón sigue edificando sus estereotipos, con base real o no, por contraste con su visión de la civilización. De este modo, destacó que entre los cántabros los hombres eran casados por las mujeres, siendo éstas dotadas por aquéllos, y heredando las hijas el patrimonio familiar (3.4.18); se establecía, de este modo, una ginecocracia. De cualquier manera, la imagen que da el de Ponto en el pasaje no es completamente bárbara, sino que muestra una vía a medio camino entre el salvajismo y la civilización. El matrimonio 'civilizado' básicamente consistía en una transacción que realizaban el padre y el futuro esposo de la mujer y de una serie de objetos, la dote, lo que en el fondo suponía un intercambio entre dos comunidades.

De esta forma, las costumbres de los cántabros quedarían a medio camino entre bárbaras - son los hombres los que resultaban intercambiados- y civilizadas - había una dote de por medio-. Otro punto a favor del equilibrio residía en el hecho de que las mujeres buscaban la esposa para el marido, pero son los hombres quienes dotaban a sus hermanas. Ante las afirmaciones de Estrabón, nos planteamos un interrogante: si son las mujeres las que trabajan $-\mathrm{y}$, por tanto, poseen- 
la tierra (3.4.17), ¿qué dote podría aportar el varón a sus hermanas? Lo más probable es que los varones se centrasen en una economía de pastoreo, complementándolo con el bandidaje y la guerra, actividades plenamente documentadas tanto por las fuentes como por la arqueología.

\section{CONCLUSIONES}

Como hemos podido apreciar, Estrabón presenta en su Geografía múltiples facetas: por un lado observamos la tradición antropológica heredada desde, al menos, el siglo $V$ a.C., la revisión crítica a algunos de sus aspectos, así como la 'versión oficial' del momento. También contemplamos que, más allá del carácter antropológico que hay presente en buena parte de la obra, lo que el autor buscaba era componer una dualidad nacida de la comparación entre el hombre civilizado y el salvaje, en la que todas las características de cada uno de los elementos nace como una contraposición al opuesto, reforzando así el contraste y la diferencia. De este modo, lo que a simple vista es algo pintoresco, como la utilización de orines para la higiene, no deja de ser el resalte del estereotipo que deja en evidencia al salvaje y eleva al hombre civilizado.

Lógicamente, y como en todo estereotipo, la imagen que construye Estrabón tiene parte de realidad y parte de ficción. La arqueología ha documentado comportamientos plenamente normalizados, por ejemplo la utilización de bellotas para la alimentación humana, en varios pueblos de la Península lbérica, mientras que otros son más propios de relatos mitológicos, como en el caso de las amazonas, mujeres de los samnitas (Strab. 4.4.5). Es en estos casos donde comprobamos las limitaciones existentes en la época, ya que donde el estudioso no podía viajar, los textos anteriores y las leyendas se convertirían en la única fuente de conocimiento.

De cualquier forma, y a modo de coda, hemos de señalar que en la mentalidad grecolatina existía una necesidad de ese bárbaro abstracto que simbolizase el reverso más negativo del hombre, para que así la imagen de la civilización resultase más brillante; no sería necesario en este caso que se correspondiese con la realidad, ya que sería algo muy difícil de comprobar o contrastar. También servía como justificación del sometimiento de estos pueblos al poder romano, bajo unas formas que dejan vagos recuerdos al imperialismo colonialista decimonónico. Podemos afirmar entonces que la creación y desarrollo de estos estereotipos responde a una necesidad demandada y que, por tanto, eran muy difíciles de derribar.

\section{BIBLIOGRAFÍA}

BERMEJO BARRERA, J. C. (1994), Mitología y Mitos de la Hispania Prerromana, 2 vols., Madrid.

CRUZ ANDREOTTI, G. coord. (1999), Estrabón e Iberia: Nuevas Perspectivas de Estudio, Málaga. 
DOMÍNGUEZ MONEDERO, A. J. (1984), «Reflexiones acerca de la sociedad hispana reflejada en la Geografía de Estrabón», Lucentum 3, 201-208.

GARCÍA BELLIDO, A. (1945), España y los Españoles hace Dos Mil Años en la Geografía de Estrabón, Madrid.

- (1978), La España del Siglo Primero de Nuestra Era (Según P. Mela y C. Plinio), Madrid. MEANA, M. J. y PIÑERO, F. eds. (1991), Estrabón. Geografía, Madrid.

MONTERO BARRIENTOS, D. (1995-96): «El determinismo geográfico, la geografía económica y el imperialismo en la obra de Estrabón», SHHA 13-14, pp. 311-330.

PLÁCIDO SUÁREZ, D. (1987-88), «Estrabón III: el territorio hispano, la geografía griega y el imperialismo romano", Habis 18-19, 243-256. 